\title{
Stupid Judgments
}

\author{
James F Welles*
}

East Marion, New York, USA

*Corresponding author: James F Welles, PhD, P.O. Box 17, East Marion, New York, USA

Submission: 㘹 February 27, 2018; Published: 眥 March 28, 2018

\section{Introduction}

We judge (i.e., evaluate) human behavior by arbitrarily selected criteria: e.g., a person may be judged a "Success" according to wealth, status, power, health, number of children, etc. The selection of the specific criterion used is culturally predetermined by the judge's background and completely arbitrary (in that two judges sitting side by side may disagree due to their backgrounds) and often irrelevant (i.e., stupid).

The fact that we are so consistently arbitrary has two major implications for the student of stupidity. Sounding Socratic, the first is that the only thing we can really know about ourselves is that we cannot really know anything about ourselves. Over 100 years of unbiased scientific studies have conclusively demonstrated that we are arbitrary creatures incapable of making unbiased studies, particularly of our own behavior. If you need evidence of our arbitrary nature, review the more than 250 competing and often conflicting theories about human nature which have been proposed by behavioral scientists. Taken together, these indicate only that human behavior is so varied that it can be interpreted according to any number of standards to support any number of causal explanations.

The second major implication of arbitrariness is that it all but guarantees we will be stupid because it inhibits our recognition of what stupid behavior is, especially when we are actively involved in it. One of the few constants about people is that we never interpret our own behavior as stupid. Were we to do so, there would undoubtedly be much less stupidity. However, as judging behavior is such an interpretive process, we tend to favor explanations which confirm our senses of pride and self-esteem while being loath to admit our idiocy if an alternative explanation can be proffered by ourselves or friends ${ }^{1}$. (Our enemies are probably equally motivated to find fault with us, but neutral bystanders might be objective if indifferent.)

To be more specific, judgment is biased by the existing schema [1], with arbitrariness and subjectivity contributing to the usually self-confirming result. First, criteria for judgment are arbitrarily selected, and then, within that context, subjective judgments are made. To continue with the example cited above, a politician would probably judge success by the criterion of power, whereas a financier might judge by wealth. Of course, wealth lends itself to objective measurement, in that money can be counted, but clever accountants can render financial affairs subjective by a little creative fudging and finagling. Likewise, the "War on Crime" can be judged by different criteria depending on the purpose of the judge: when justifying the existing budget, emphasis is placed on the success of existing law enforcement programs; on the other hand, when soliciting an increase in supporting funds, emphasis is placed on the extent threat of crime in society [2].

A final consideration in judging stupidity is timing-when the evaluation is made. A case in point was created by post-WWI Russian and Germany who connived to contravene the restrictions of the Versailles Treaty against the Wehrmacht having tanks in Germany by having the Germans help the Russians build tanks in Russia, which both countries then used for training purposes there. This arrangement continued through the 1920's into the early 1930's. Judged in June, 1941, it was incredibly stupid of Russians to have been party to the deal, but three years later, it was Germans who were adjudged to be the stupider of the erstwhile partners as Russian tanks poured into their country [3].

In general, whatever stupidity is, it is induced by the biased judgments a person's schema imposes on his experiences and perceptions, as is illustrated by an anecdote about a confrontation between an alcoholic ballplayer and his reform minded manager. The manager called the player into his office one afternoon and placed an earthworm in a glass of water. The worm wriggled around quite happily until placed in a second glass containing alcohol, whence it promptly shriveled up and died. "See that?" exclaimed the manager. "Sure," replied the player. "If you drink, you won't have worms."

${ }^{1}$ In a similar way, our subjectivity makes it possible for us to indulge in behavioral excesses. Most cultural trends (development, stagnation, exploitation, etc.) become stupid as they go to maladaptive excess, and they commonly go to such excess precisely because those responsible for them are too emotionally involved to judge their unintended, long-term effects objectively. 
The single, obvious lesson to be drawn here is that there is no single, obvious lesson to be drawn from what we perceive and do. Each person draws his own conclusions to suit himself, and this is where the behaviorists' stimulus response model fails because what behavior a stimulus induces, for example, is so unpredictable. For example, communal poverty might be perceived as a stimulus for programs of economic development or simply something to escape [4]. This, in turn, neutralizes Hebb's Rule that correct decisions rein force neural pathways [5] because what is correct is likewise so subjective.

Although success is a reward and failure is a punishment, just what exactly is being rewarded or punished (and even what constitutes success or failure or even what constitutes a reward or punishment) ${ }^{2}$ is never quite clear, since we can draw the damndest con-clusions as to what is going on in our perceptual world [6]. For example, Saddam Hussein perceived the Mother-of-All-Battles (i.e., when he got thrown out of Kuwait in 1991) as a great victory for Iraq. It takes an overwhelmingly unequivocal victory, as in 2003 , to win a war of ideas against someone with that kind of mentality [7]. Further, in a general sense, it shows that facts are secondary to myths in influencing behavior. Finally, as psychologist Winston Churchill noted, sometimes we are helped (rewarded) by our mistakes and injured (punished) by our successes [8]. An unfortunate, obscure example of this latter principle was provided by the vilification and demotion of the heroic Australians who saved their country by defeating an advancing Japanese force on the Kokoda Trail on New Guinea in 1942: [9] they were basically overachievers who were underappreciated if not resented by the brass back at HQ for showing them up.

To expand on the point of the subjective nature of rewards and punishments, there may be disagreement if not confusion as to what constitutes good and bad, right and wrong-indeed reality and fantasy [10]. For example, in post Saddam Iraq, there was considerable debate as to what was going on, why we were there, what we were doing there, what we should have been doing there, how we should go about it, if we should go about it, etc [11]. So, what was good or bad? Right or wrong?

Usually, the mind shapes perceptions by structuring (according to a given emotional disposition) the ways objects and events are construed and represented [12]. By this manner, experiences commonly teach us lessons which are inherently biased toward the existing schema. As we are inclined to assume credit for anything positive and attribute blame elsewhere for anything negative that occurs around us [13], we tend to become better adapted to ourselves than to our environment. It is this positive feedback system between our judged actions and beliefs which induces us to persist in self-confirming behavior which others construe as stupid but which we can and do consider as necessary or intelligent.
In the biased world of arbitrary judgments, it is easy to label an act as "Intelligent" if it can be and is construed as successful. However, the evaluation of a person's mentality according to the results of his behavior can be misleading. Consistent with humanity's tendency to flatter itself, we usually attribute to intelligence significant discoveries simply because they are considered major achievements in the development of civilization. Many of these were really just accidental and in no way due to foresight, planning or directed thinking. No one sat down to plan out how to control fire. America was discovered by Norsemen who could not turn their boats around, Columbus searching for Asia and Frenchmen following the cod [14]. Every step Dalton took to his atomic theory was either logically inconsistent or wrong [15], and the discovery of penicillin was made possible by sloppy lab technique [16]. As beneficial as these events were, none of them exemplifies intelligence in any way.

Similarly, the term "Stupidity" is often used to indicate a behavioral strategy that failed, although all failures are not necessarily stupid. For example, a failure really does not reflect stupidity if it was due to the influence of unknowable factors. Failure may properly be regarded as stupid when it is caused by the application of an inappropriate schema or the misapplication of an appropriate schema to a problem. (Of course, a compounding occurs when an inappropriate schema is misapplied.) Earlier, we reviewed briefly the mechanical malfunctioning (i.e., ignoring data, misperceiving data, faulty symbolizing, etc.) which can contribute to maladaptive behavior. However, our most profound interest is not in the incidental breakdown of relevant schemas but in the deleterious nature of the social psyche which tends to make all belief systems and their behavioral sets maladapted to each other and the environment.

\section{References}

1. Lewicki P, Goleman D (1992) Quoted in your unconscious mind may be smarter than you. The New York Times C11.

2. Mc Williams P (1993) Ain't nobody's business if you do. Prelude Press Los Angeles, CA, USA, p.185.

3. Fawcett B (2010) Mistakes that changed history. Berkley Books New York Chap p. 64.

4. Snyder T (2010) Quoted Judt T. Thinking the Twentieth Century. Penguin New York, USA, p. 357.

5. Hebb D (1949) The organization of behavior.

6. Lewis M (2017) The undoing project. Norton New York, USA, p. 70.

7. British Broadcasting Company (2001) Biography of Saddam Hussein.

8. Churchill W (1932) Thoughts and adventures. Thorn-ton Butterworth London, UK, p. 15

9. Bradley J (2009) The boys who saved Australia. In what if? Cowley R (Ed.), Putnam New York, USA, p. 690.

${ }^{2}$ Durants (1967) Jean-Jaques Rousseau's schoolteacher punished naughty boys by paddling their Fannies until she noticed J-J was misbehaving to get paddled. This complicates Jeremy Bentham's utilitarianismthe greatest good for the greatest number significantly p. 6. 
10. (1964) For a probing take on this general problem see the outrage starring paul newman and clair bloom. A westernized Rashomon.

11. Woodward B (2008) The war within. Simon and Schuster New York, USA, p. 24.

12. Ayduk O, Mischel W (2002) when smart people behave stupidly. In: Why smart people can be so stupid, Sternberg R (Ed.), Yale University Press, New Haven, CT, USA, p. 101.

13. Lau R, Russel D (1980) Attribution in the sports pages. J of Personality and Social Psychology 39: 29-38.
14. Pitkin W (1932) A short introduction to the history of human stupidity. Simon and Schuster, New York, USA, p. 14.

15. Holton G (1953) On the duality and growth of physical science. American scientist 41,91. Dalton laid down the mutable law that no one could split an atom, p. 150.

16. Fawcett. Op cit, p. 65.

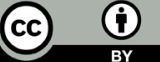

Creative Commons Attribution 4.0 International License

For possible submissions Click Here
Submit Article

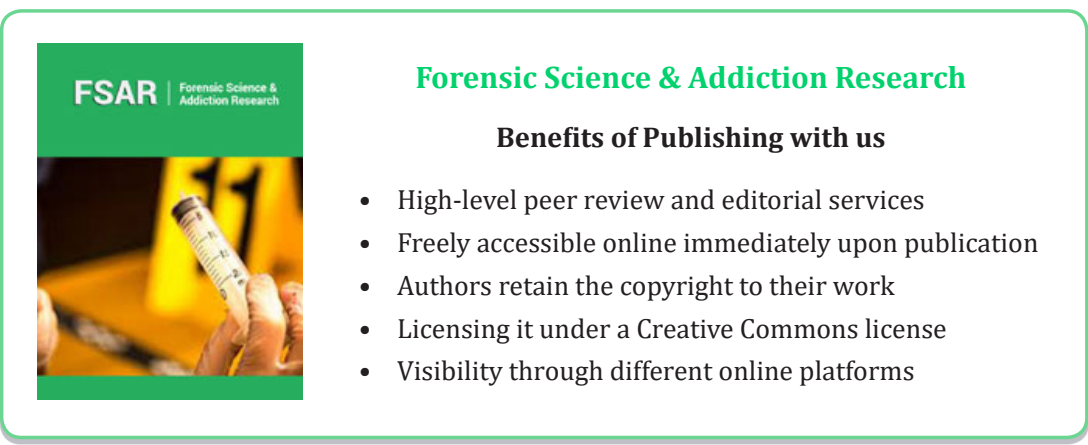

